Claire Murphy, Nagarajan Ramamoorthy, Patrick C. Flood, Sarah MacCurtain*

\title{
Organizational Justice Perceptions and Employee Attitudes among Irish Blue Collar Employees: An Empirical Test of the Main and Moderating Roles of Individualism/Collectivism ${ }^{* *}$
}

Prior research indicates that individualism - collectivism orientations (I/C) of employees, as well as organizational justice perceptions - procedural and distributive justice perceptions - influence the following employee attitudes: affective/normative commitments, pro-social behaviour, team loyalty, and tenure intent. Research also suggests that I/C orientations are related to justice perceptions with individualism orientation favouring equity principle and collectivism orientation favouring equality principles. Under the assumption that individualism orientation favours equity and procedural justice principles, we empirically test the main effects of $\mathrm{I} / \mathrm{C}$ orientations and justice principles on employee attitudes. In addition, we also test whether I/C orientations moderate the relationships between justice perceptions and these employee attitudes. We tested these hypotheses using a survey methodology consisting of a sample of two-hundred and four employees from Ireland. Implications for research and practice are discussed.

Key words: Individualism/Collectivism Orientations, Organizational Justice Perceptions, Employee Attitudes

* Claire Murphy, Department of Personnel and Employment Relations, University of Limerick, Plassey Technnological Park, Limerick, phone: +353-87-8232552, e-mail: claire.murphy@ul.ie.

Nagarajan Ramamoorthy, University of Houston - Victoria, 14000 University Boulevard, Sugar Land, TX 77479., phone: +1 (281) 275-3381, e-mail: ramamoorthyn@uhv.edu.

Patrick C. Flood, Department of Personnel and Employment Relations, University of Limerick, Plassey Technnological Park, Limerick, phone: +353-87-8232552,

e-mail: Patrick.Flood@ul.ie.

Sarah MacCurtain, Department of Personnel and Employment Relations, University of Limerick, Plassey Technnological Park, Limerick, phone: +353-87-8232552, e-mail: Sarah.Maccurtain@ul.ie.

** Article received: April 28, 2006

Revised version accepted after double blind review: July 5, 2006. 


\section{Introduction}

Perceptions of justice or fairness in the workplace are widely recognised as influencing a variety of employee attitudes in organisational research (Adams 1965; Cropanzano/Greenberg 1997; Fields/Pang/Chiu 2000; Leventhal 1976; Ramamoorthy/ Flood 2004). Further, recent research indicates that organisational justice consists of three distinct but related components: distributive, procedural, and interactional justice. Distributive justice refers to the fairness of the decision outcome and is grounded in equity theory literature (Adams 1965). Procedural justice, on the other hand, relates to the perceived fairness of the decision-making procedures used to determine the distribution of the outcome and is based on literature concerning dispute resolution models (Kim/Mauborgne 1997; Leventhal 1976; Thibaut/Walker 1975). Finally, interactional justice refers to the perceived quality and fairness of the interactions between the employee and his/her supervisor (Ramamoorthy/Flood 2004). In particular, distributive justice and procedural justice have been shown to be consistently related to employee work-related attitudes and behaviours such as job satisfaction, organisational commitment, pro-social behaviours, tenure intent, team attachment, job performance and absenteeism (Colquitt/Conlon/Wesson/Porter/Ng 2001; Greenberg 1990; Lee/Pillutla/Law 2000; Phillips 2002).

Research on justice perceptions has been predominantly conducted in the Western, individualistic societies. Yet, research on cultural orientations (Gomez-Mejia/ Welbourne 1991) indicates that norms of justice principles are culture bound and that individualistic cultures emphasize equity whereas collectivistic cultures emphasize equality. That is, distributive justice perceptions may be different across individualistic versus collectivistic cultures. Specifically, adherence to equity norms based on pay-forperformance principles may be more compatible with individualism orientations and adherence to equality norms may be more compatible with collectivist orientations. While studies examining the effect of cultural differences on distributive justice norms are plentiful, studies examining differences in procedural justice perceptions across cultures are rather sparse. However, Ramamoorthy/Carroll (1998) proposed that formal performance appraisal procedures incorporating procedural justice principles may be more characteristic of individualistic cultures than collectivistic cultures. Further, they suggested that collectivistic cultures use informal mechanisms to manage employee performance (e.g., assigned performance goals, group goals as opposed to individual goals, feedback through peers or one's work-group or evaluation of performance by group members). To the extent performance appraisals form a critical aspect of reward allocations, such informal practices may be contradictory to the procedural justice principles espoused in individualistic, Western societies. Therefore, these authors implicitly suggested that formal organizational systems incorporating procedural justice principles may be more appropriate for individualistic cultures and may not be appropriate for collectivistic cultures. Pillai, Tan, and Williams (2001) also reported that procedural justice principles did not have any effect on commitment and tenure intent among collectivistic Indians compared to individualistic Germans or US employees. Thus, evidence suggests that distributive and procedural justice principles may differ as a result of one's individualism versus collectivism orientation. 
In addition to differences in justice norms across cultures differing on individualism versus collectivism orientations (I/C), studies on $\mathrm{I} / \mathrm{C}$ orientations show that intracultural variations among individuals within a culture may exist and that such variations are related to a variety of employee attitudes (Parkes/Bochner/Schneider 2001; Ramamoorthy/Carroll 1998). Hence, it would be reasonable to expect that differences in $\mathrm{I} / \mathrm{C}$ orientations may also result in differences in adherence to and preferences for different distributive and procedural justice norms. That is, individuals with a higher individualism orientation may be more receptive and adhere to equity principles and procedural justice principles than individuals with a higher collectivism orientation. Yet, to our knowledge, no study has examined whether I/C orientations of individuals moderate the relationships between justice principles and attitudes towards the organization (commitment and tenure intent) or towards work behaviours in teams (loyalty and pro-social behaviours). In the present study, therefore, we are examining the effects of organizational justice perceptions and $\mathrm{I} / \mathrm{C}$ orientations on the following employee attitudes: affective commitment, normative commitment, tenure intent, pro-social behaviour, and team loyalty. Further, we are also examining whether $\mathrm{I} / \mathrm{C}$ orientation moderates the relationships between distributive justice and procedural justice and the outcome variables suggested above. We have chosen these variables as prior research shows that commitment and tenure intent are important organizational level outcomes and pro-social behaviour and team loyalty are critical teamlevel outcomes. These research questions were tested using a sample of two-hundred and four blue collar employees from the Shannon region of Ireland from ten different organizations. Primarily, we used a survey methodology to address these research questions.

The present paper is organized into four sections. First, we review the literature relating to $\mathrm{I} / \mathrm{C}$ and justice principles from which we draw our hypotheses. We follow this with a presentation of the methodology used to test these hypotheses. We then present the results of our study followed by a discussion of implications for research and practice.

\section{Review of the literature}

\section{I/Corientations and employee attitudes}

Hofstede (1980) examined the issue of national cultural differences and discovered that cultures differed along individualism/collectivism, power distance, masculinity femininity and uncertainty avoidance dimensions. Among the four dimensions, I/C dimension has been of most interest to the field of management literature. An individualistic orientation refers to a tendency to define oneself as an entity consisting of a single person and emphasizes the attainment of individual goals, competition and autonomy. A collectivist orientation on the other hand refers to a tendency to define self as part of a larger collective or unit, such as a member of a social group and emphasizes the attainment of group goals, co-operation and the subjugation of individual needs to the needs of the group as a whole. Though Hofstede (1980) conceptualized $\mathrm{I} / \mathrm{C}$ orientation as a national level construct, in recent years, research has demonstrated that intra-cultural variations in I/C orientation may also exist (Clugston/ Howell/Dorfman 2000; Ramamoorthy/Carroll 1998; Vandello/Cohen 1999). 
Several studies suggest that I/C orientations may be associated with work-related outcomes such as commitment, tenure intent, loyalty or pro-social behaviour. GomezMejia and Wellbourne (1991) suggested that the nature of employment relationship in collectivist societies tend to be based on moralistic principles. Consequently, employees are expected to be more loyal, committed to the organization and/or social groups such as teams that they belong to and tend to exhibit longer employment tenure than in individualistic entities where the employment relationship is based on the premise of agency and is contractual in nature. Further, engaging in extra role behaviours such as pro-social behaviours are generally expected of employees in collectivist societies since organizations' and groups' interests take precedence over individual interests. Parkes et al., (2001) also reported that collectivists tended to be more committed to their organization and exhibited longer tenure than their individualistic counterparts. Ramamoorthy and Flood (2002) reported that I/C orientations were related to loyalty to the team. Therefore we hypothesise that:

H1: Individualism orientation will be negatively related to affective commitment, normative commitment, tenure intent, pro-social behaviour and team loyalty.

\section{Organizational justice principles and employee attitudes}

Generally speaking, organizational justice refers to perceived fairness in the workplace and comprises of distributive, procedural, and interactional justice (Greenberg 1990). Distributive justice perception is concerned with the perceived fairness of the outcome grounded in Adam's (1965) equity theory. Although Adam's equity theory is concerned with an evaluation of one's own inputs and outcomes with that of comparison others, distributive justice may also involve an evaluation of one's own performance or effort and the associated rewards without any specific reference to comparison others. Equity, distributive justice, and pay for performance have been used interchangeably in the literature and consist of matching outcomes such as rewards or promotions to inputs such as effort, responsibility, or job performance or education (Ahmad 2004). Procedural justice is based on dispute resolution models (Thibaut/Walker, 1975) and is concerned with the fairness of the procedures used in the distribution of the outcome. This dimension of justice is concerned with the processes used by organizations to allocate rewards and may consist of adequate notice about performance expectations, clear communications of these standards, involvement of the supervisors and subordinates in the setting of performance standards, periodic review of task accomplishment, accurate performance feedback, and an opportunity to resolve grievances with the supervisors. Both distributive and procedural justice perceptions have been shown to positively influence employee attitudes such as organizational commitment, tenure intent, and pro-social behaviours.

In a meta-analytic study, Colquitt et al., (2001) reported that the three types of organisational justice perceptions were correlated with each other and all three justice dimensions were related to job satisfaction, organizational commitment, evaluation of authority, pro-social behaviours, and employee withdrawal behaviours. CohenCharash/Spector (2001) reported that distributive justice was related to affective commitment and intent to stay with the organisation but unrelated to job performance. Another study reported that both procedural and distributive justice were related 
to organizational commitment but only distributive justice was related to turnover intentions (Hendrix/Robbins/Miller/Summers 1999). Sweeney and McFarlin (1993) and Tremblay, Sire, and Balkin (2000) also reported that the relationships with pay satisfaction and organisational satisfaction were stronger for distributive justice than procedural justice. Studies show that lower levels of perceived procedural justice may result in lower job satisfaction (Fields/Pang/Chiu 2000), lower levels of employee commitment (Flaherty/Pappas 2000; Rhoades/Eisenberger/Armeli 2001), unwillingness to help other employees (Spector/Fox 2002; Moorman 1991), lower levels of trust (Aquino/Griffith/Allen/Hom 1997; Kim/Mauborgne 1998;) and may result in increased intention to leave and actual employee turnover (Konovsky/Cropanzano 1991; Roberts/Coulson/Chonko, 1999; Zellars/Briu/Bratton/Brymer/Perrewe 2004). Such negative attitudinal and behavioural consequences may ultimately impact the performance of the individual (Colquitt et al. 2001) and the organisation as a whole (Zellars et al. 2004). Further, procedural justice has been shown to predict prosocial behaviour (Masterson/Lewis/Goldman/Taylor 2000; Williams/Pitre/Zainuba 2002). It has also been associated with evaluation of supervision (Fields et al. 2000), affective commitment, intent to stay with an organisation and job performance (Cohen-Charash/Spector 2001). Thus, overall evidence seems to indicate that both procedural justice and distributive justice perceptions positively affect employee attitudes. In light of this, we propose that:

H2: Distributive justice perceptions will be positively related to affective commitment, normative commitment, tenure intent, pro-social behaviour and team loyalty.

H3: Procedural justice perceptions will be positively related to affective commitment, normative commitment, tenure intent, pro-social behaviour and team loyalty.

\section{The moderating effects of $I / C$ orientations}

Greenberg (2001) suggests that organizational justice is grounded in norms and that such norms can vary widely across cultures. Prior studies have shown that preference for equity is more congruent with individualistic orientation (Ahmad 2004; Bond/ Leung/Choi, 1982; Kim/Park/Suzuki 1990). Individualists' preference for equity in the distribution of rewards is generally attributed to a concern with promoting productivity and task achievement, while collectivists' preference for equality is attributed to a concern with maintaining group harmony. Collectivistic cultures are less concerned with individual standing or the amount that each individual receives than members of individualistic cultures. Deutsch (1975) categorized this as the equality rule, which indicates members' deep concern about assuring interpersonal harmony, and focusing less on differentiation in individual rewards. In support of this assertion, for example, subjects from Hong Kong preferred less equitable allocations among group members than their U.S. counterparts (Bond et al., 1982). Similarly, Berman, Murphy-Berman, and Singh (1985) reported that collectivist Indians subscribed to equity norms less and need norms more than their US participants. Similarly, collectivist Koreans were also found to show less preference for equity than the more individualistic U.S. samples in the allocation of social rewards (Kim et al. 1990). 
Further, the results of the study by Ramamoorthy and Flood (2002), indicate that a higher level of individualism orientation results in more positive attitudes towards the team, willingness to expend effort, pro-social behaviour and tenure intent under conditions of higher distributive justice than under lower distributive justice perceptions. That is, distributive justice perceptions may not be universal and that different individuals may react differently towards distributive justice in the workplace. This would suggest that collectivists who perceive higher distributive justice levels within the organisation are less likely to have positive employee attitudes than those with individualist orientations as equity principles may not be congruent with their value systems. Such results are consistent with the literature on I/C as individualism emphasizes personal outcomes and individual achievements, and collectivism emphasizes group outcomes and group harmony. Therefore, violations of equity norms may evoke different responses from individuals with a higher level of individualism orientation than a higher level of collectivism orientation. In light of the above, we propose that:

H4: A higher level of distributive justice perceptions should result in a higher level of affective commitment, normative commitment, tenure intent, pro-social behaviour, and team loyalty under conditions of a higher level of individualism orientation than under a higher level of collectivism orientation.

While several studies have examined the relationship between I/C orientations and distributive justice perceptions, studies on the relationship between I/C orientations and procedural justice perceptions are rather sparse. However, there are strong reasons to believe that individualists may view procedural justice more positively than collectivists due to its emphasis on individual rights. Procedural justice literature (Thibaut/Walker 1975) suggests that fair procedures such as adequate notice, fair hearing, consistent application of rules, and suppression of bias provide the employees a certain level of control over the process. Further, such processes essentially imply a formal mechanism of procedures than informal mechanisms to resolve disputes.

Procedural justice literature, as is commonly referred to, has a stronger emphasis on individual's rights and interests than collective right and interest. Anecdotal evidence may also support our contention that individualism orientation may be positively related to a preference for procedural justice. Ramamoorthy and Carroll (1998) reported that formal performance appraisal systems emphasizing individual's rights (e.g., participative goal setting for the individual, periodic review and feedback, opportunity to jointly resolve appraisal rating differences) were more positively related to individualism orientation than collectivism orientation. They further reported that a higher level of collectivism orientation was positively related to informal feedback through group members, assigned goals for the team rather than individuals, and supervisory rating without any mechanism or opportunity for dispute resolutions. Since individualism values fair outcomes for the individual and fair procedures are likely to result in fair outcomes for the individual, it may make an intuitive sense to suggest that individualism orientation should also favour procedural justice or control over the process. As collectivism emphasizes group rather than individual outcomes, emphasis on procedural justice principles with its basis in individual rights, may not find favour with employees with a higher level of collectivism orientation. In light of these suggestions, we hypothesise that: 
H5: A higher level of procedural justice perceptions should result in a higher level of affective commitment, normative commitment, tenure intent, pro-social behaviour, and team loyalty under conditions of a higher level of individualism orientation than under a higher level of collectivism orientation.

In the next section, we will describe the methodology used by us to test these hypotheses.

\section{Method}

\section{Sample and Procedure}

Twenty-four manufacturing organisations in the Shannon/Limerick region of Ireland were contacted to participate in the study. These organisations were engaged in the manufacture of computer accessories and telecommunications equipment, light engineering, medical devices and primary raw materials. Of these twenty-four organizations, ten organizations agreed to participate in the study and it was mostly personal contacts within the organisations that facilitated participation in the study. In all, twohundred-and-four (204) blue-collar employees from these organisations completed the survey. Because the participating organisations allowed employees to complete the survey during working hours, the response rate was approximately 95\%, barring a few employee absences. Companies that declined to participate cited a variety of reasons such as peak-work, timing and confidentiality issues. Of the two-hundred-and-four blue-collar employees, one-hundred and eleven respondents (54.4\%) were male and ninety-three respondents $(45.6 \%)$ were female. Further, fifty-eight $(28.4 \%)$ employees were aged between 18 and 25, seventy-one (34.8\%) were aged between 26 and 35, forty-nine (24\%) were aged between 36 and 45 , nineteen $(9.3 \%)$ were aged between 46 and 55 and seven $(3.4 \%)$ were over 55 .

\section{Measures}

Individualism/collectivism: We measured I/C orientations using the nineteen-items Likert-type scale of Wagner (1995) and subsequently validated by Ramamoorthy and Carroll (1998). Respondents were asked to indicate the extent to which they agreed or disagreed with various statements purported to measure I/C orientations with " $1=$ strongly disagree and $5=$ strongly agree" as anchors. The data coding was done such that a higher score indicated a higher level of individualism orientation. This scale captures the multi-dimensional nature of I/C orientations such as competitiveness, selfreliance, supremacy of individual goals, supremacy of individual interests, and solitary work preferences. This scale yielded a Cronbach's alpha of 0.78 .

Equity Perceptions: We measured equity perceptions (equity) using the two items from Ramamoorthy and Flood (2004). These two items were: "I am fairly rewarded for the amount of responsibility I take on" and "I am fairly rewarded for the amount of effort I put in" with "1 = Strongly Disagree" and "5 = Strongly Agree" as anchors. These two items exhibited a Cronabach's alpha of 0.89. A higher score on this variables indicates a higher level of perceived equity in reward distributions.

Procedural Justice Perceptions: We measured procedural justice perceptions using the five-items composite scale from Ramamoorthy, Flood, Slattery, and Sardessai (2005). Responses were gathered on a five-point Likert scale, which ranged from $1=$ strongly disagree to $5=$ strongly agree. Participants were asked to indicate the extent to which 
they agreed or disagreed with statements such as "The performance standards or criteria used in the allocation of rewards are very clearly communicated to employees" and "When I feel that I have not been fairly rewarded, I can resolve it through discussion with my supervisor". The data was coded such that a higher score indicated higher level of procedural justice perceptions. This five-item scale yielded a reliability coefficient of 0.74 .

Team loyalty: We measured team loyalty using two items. Responses were collected on a five-point Likert-type scale, which ranged from " $1=$ strongly disagree to 5=strongly agree" as anchors. Participants were asked to indicate the extent to which they agreed or disagreed with the following statements: "I am loyal to my team" and "I expect to work with my colleagues for a long period of time". Data coding was done such that a higher score indicated a higher level of team loyalty. This two-item scale yielded an alpha reliability coefficient of 0.61 .

Pro-social behaviour: We measured pro-social behaviour using five items. Responses were given on a five-point Likert scale, which ranged from " $1=$ strongly disagree to $5=$ strongly agree" as anchors. Participants were asked to indicate the extent to which they agreed or disagreed with statements such as "I help my co-workers with my knowledge and expertise when they need me" and "Even when it does not personally benefit me, I do things for the benefit of the company". Data were coded in such a way that a higher score indicated a higher level of pro-social behaviour. The five items yielded an alpha coefficient of 0.82 .

Normative Commitment: We measured normative commitment using six items from Meyer/Allen (1991). Responses were collected on a five-point Likert scale, which ranged from " $1=$ strongly disagree to $5=$ strongly agree" as anchors. Participants were asked to indicate the extent to which they agreed or disagreed with statements such as "I do not feel any obligation to remain with my current employer" (reversed) and "I would not leave my company right now because I have a sense of obligation to the people in it". Data were coded in such a way that a higher score indicated a higher level of normative commitment. The six items yielded an alpha coefficient of 0.79 .

Affective commitment: We measured affective commitment using the five items from Mowday, Porter, and Steers (1979) Organizational Commitment Questionnaire. Responses were collected on a five-point Likert scale, which ranged from " $1=$ strongly disagree to 5=strongly agree" as anchors. Participants were asked to indicate the extent to which they agreed or disagreed with statements such as "I am proud to tell others I am part of my company" and "I really care about the fate of my company". Data were coded in such a way that a higher score indicated a higher level of affective commitment. The five items yielded an alpha coefficient of 0.84 .

Tenure Intent: We measured intent to remain with the company using two items. The first item was a dichotomous item in which we asked the employees to indicate whether they intend to remain with their employers for less than three years (coded as 1) or more than three years (coded as 2). The second item asked respondents to indicate how long they intended to stay with their employer with $1=$ less than one year and $6=$ more than 5 years. A confirmatory factor analysis indicated that the two items loaded on a single factor, with a loading of 0.96 . In order to form the composite score, we normalized the 
score on each of these items and then took the mean of the two items as an indicator of tenure intent. A higher score on this variable indicated a greater intent to stay with the employer. The Cronbach's alpha for these two items was 0.93.

Control variables: Employees' age and gender were used as control variables in testing our hypotheses. We coded employees' gender as $1=$ female and $2=$ male. Employees' age was measured using an ordinal scale with $1=18-25$ years, $2=26-35$ years, $3=36-45$ years, $4=46-55$ years and $5>55$ years.

\section{Data analyses strategy}

To briefly recapitulate the hypotheses developed in this study, hypotheses 1 to 3 propose that I/C orientations, distributive, and procedural justice perceptions will have positive effects on the following outcome variables: affective commitment, normative commitment, tenure intent, pro-social behaviour, and team loyalty. Hypotheses 4 and 5 propose that I/C orientations moderate the relationships between distributive justice and the outcome variables and procedural justice and the outcome variables included in this study.

In order to test these hypotheses, we used moderated regression analyses suggested by Pedhazur (1982). As suggested by Pedhazhur (1982), in the moderated regressions, in the first step, the control variables were entered into the equation as covariates. In the second step we entered I/C orientations, and in the third step, we entered reward fairness and procedural justice perceptions. Finally, in the fourth step we entered the interaction terms between the I/C and justice perceptions: I/C $\mathrm{x}$ distributive justice and $\mathrm{I} / \mathrm{C} \mathrm{x}$ procedural justice. Positive and statistically significant betas for distributive justice, procedural justice, and I/C orientation variables should render support for hypotheses 1 to 3. If the interaction terms are statistically significant, then we derive support for hypotheses 4/5.

We used the F-ratio test for incremental variance (Pedhazhur 1982) to test for the statistical significance of the set of variables entered in each step. That is, if the incremental variance explained by the interaction terms are not statistically significant, then we have to rule out the interaction effects between $\mathrm{I} / \mathrm{C}$ and justice perceptions. To test for the significance of the betas, we used one-tailed t-tests.

\section{Results}

Table 1 presents the means, standard deviations and correlations among the variables used in the study.

In the moderated regression analyses, multi-collinearity arising out of a high correlation between the predictor variables used to create the interaction terms may be potentially problematic. Since the correlations between I/C and reward fairness and $\mathrm{I} / \mathrm{C}$ and procedural justice perceptions are non-significant, we can rule out the effect of multi-collinearity among the predictor variables used in our study. Table 2 presents the results of the moderated regression analyses.

$\mathrm{H} 1$ proposed that $\mathrm{I} / \mathrm{C}$ orientation will be negatively related to the two forms of commitment, team loyalty, tenure intent, and citizenship behaviours. As predicted, a higher level of individualism orientation resulted in a lower level of affective commitment $(\beta=-.17, \mathrm{p}<.01)$, tenure intent $(\beta=-.13, \mathrm{p}<.05)$, pro-social behaviour $(\beta=-$ 
$.62, \mathrm{p}<.05)$ and team loyalty $(\beta=-.84, \mathrm{p}<.01)$. However individualism orientation appeared to be unrelated to normative commitment. Thus, H1 received a dominant but partial support.

Table 1: Means, standard deviations, and correlations among the variables

\begin{tabular}{|c|c|c|c|c|c|c|c|c|c|c|c|}
\hline Variables & Mean & S.D. & 1 & 2 & 3 & 4 & 5 & 6 & 7 & 8 & 9 \\
\hline 1. Gender & 1.46 & 0.50 & & & & & & & & & \\
\hline 2. Age & 2.25 & 1.07 & $-.20^{* *}$ & & & & & & & & \\
\hline $\begin{array}{l}\text { 3. Individua- } \\
\text { lism }\end{array}$ & 2.48 & 0.49 & $0.15^{*}$ & 0.16 & & & & & & & \\
\hline $\begin{array}{l}\text { 4. Procedu- } \\
\text { ral Justice }\end{array}$ & 3.01 & 0.79 & $0.14^{*}$ & 0.00 & 0.06 & & & & & & \\
\hline $\begin{array}{l}\text { 5. Equity } \\
\text { Perceptions }\end{array}$ & 2.98 & 1.04 & $-.14^{*}$ & $0.13^{*}$ & -.09 & $0.31^{* \star *}$ & & & & & \\
\hline $\begin{array}{l}\text { 6. Pro-social } \\
\text { behaviour }\end{array}$ & 3.77 & 0.61 & 0.09 & 0.02 & $-.22^{\star *}$ & $0.20^{* *}$ & $0.20^{* *}$ & & & & \\
\hline $\begin{array}{l}\text { 7. Affective } \\
\text { Commitment }\end{array}$ & 3.61 & 0.75 & 0.02 & $0.15^{\star}$ & $-.19^{\star *}$ & $0.39^{* * *}$ & $0.39^{* * *}$ & $0.54^{* * *}$ & & & \\
\hline $\begin{array}{l}\text { 8. Normative } \\
\text { commitment }\end{array}$ & 2.75 & 0.70 & -.02 & $0.25^{\star * \star}$ & 0.09 & $0.21^{* *}$ & $0.34^{* * *}$ & $0.36^{* * *}$ & $0.44^{* * *}$ & & \\
\hline $\begin{array}{l}\text { 9. Team loy- } \\
\text { alty }\end{array}$ & 3.93 & 0.75 & -.02 & $0.21^{* *}$ & $-.27^{\star \star *}$ & $0.14^{*}$ & $0.15^{\star *}$ & $0.36^{* * *}$ & $0.58^{* * *}$ & $0.35^{\star \star *}$ & \\
\hline $\begin{array}{l}\text { 10. Tenure } \\
\text { Intent }\end{array}$ & 0.00 & 1.00 & -.09 & $0.26^{\star * *}$ & -.10 & $0.23^{* *}$ & $0.25^{* * *}$ & 0.05 & $0.42^{* \star *}$ & $0.23^{* *}$ & $0.42^{* * *}$ \\
\hline
\end{tabular}

${ }^{*} p<.05^{* *} p<.01{ }^{* * *} p<.001$

Table 2: Results of the moderated regression predicting affective commitment, normative commitment, tenure intent, pro-social behaviour and team loyalty

\begin{tabular}{|c|c|c|c|c|c|}
\hline Variables & $\begin{array}{c}\text { Affective } \\
\text { Commitment }\end{array}$ & $\begin{array}{c}\text { Normative } \\
\text { Commitment }\end{array}$ & Tenure Intent & $\begin{array}{l}\text { Pro-Social } \\
\text { Behaviour }\end{array}$ & Team Loyalty \\
\hline & $\beta$ (t-statistic) & $\beta$ (t-statistic) & $\beta$ (t-statistic) & $\beta$ (t-statistic) & $\beta$ (t-statistic) \\
\hline \multicolumn{6}{|l|}{ Step 1} \\
\hline Gender & $0.04(0.62)$ & $-.06(0.92)$ & $-.06(0.83)$ & $0.08(1.12)$ & $0.01(0.17)$ \\
\hline Age & $0.12(2.04)^{*}$ & $0.22(3.34)^{\star \star *}$ & $0.28(3.99)^{\star * *}$ & $0.03(0.47)$ & $0.23(3.58)^{* * *}$ \\
\hline$\Delta \mathbf{R}^{2}$ & .02 & .07 & .08 & .01 & .04 \\
\hline$F_{2,201}$ & 2.43 & $7.90^{* * *}$ & $8.67^{* * *}$ & 0.85 & $4.61^{* *}$ \\
\hline \multicolumn{6}{|l|}{ Step 2} \\
\hline I/C orientation & $-.17(2.92)^{\star *}$ & $-.04(0.57)$ & $-.13(1.87)^{*}$ & $-.62(2.20)^{\star}$ & $-.84(3.04)^{\star *}$ \\
\hline$\Delta \mathbf{R}^{2}$ & .06 & .01 & .02 & $.07^{\star \star \star}$ & .12 \\
\hline$F_{1,200}$ & $12.59^{* * *}$ & 1.67 & $4.76^{*}$ & 17.66 & $28.58^{* * *}$ \\
\hline \multicolumn{6}{|l|}{ Step 3} \\
\hline Equity Perceptions & $0.24(3.90)^{\star \star \star}$ & $0.23(3.35)^{\star \star \star}$ & $0.16(2.18)^{*}$ & $0.48(1.51)$ & $0.38(1.21)$ \\
\hline Procedural justice & $0.39(6.26)^{\star \star *}$ & $0.25(3.67)^{\star \star *}$ & $0.14(1.98)^{*}$ & $-.36(1.33)$ & $-.52(1.99)^{\star}$ \\
\hline$\Delta \mathbf{R}^{2}$ & 0.26 & .14 & .06 & .02 & .06 \\
\hline$F_{2,198}$ & $39.19^{* * *}$ & $18.26^{* * *}$ & $6.31^{* *}$ & $12.17^{* * *}$ & $7.21^{\star \star *}$ \\
\hline \multicolumn{6}{|l|}{ Step 4} \\
\hline I/C X Equity & & & & $-.44(1.22)$ & $-.40(1.16)$ \\
\hline $\begin{array}{l}\text { I/C X Procedural } \\
\text { Justice }\end{array}$ & & & & $0.86(2.43)^{*}$ & $1.03(2.98)^{\star *}$ \\
\hline$\Delta \mathbf{R}^{2}$ & .00 & .00 & .001 & .03 & .03 \\
\hline$F_{2,196}$ & 0.02 & 0.06 & 0.08 & $3.11^{*}$ & $4.50^{*}$ \\
\hline
\end{tabular}

${ }^{*} p<.05^{* *} p<.01{ }^{* * *} p<.001$ 
H2 proposed that equity perceptions will be positively related to the two forms of commitment, team loyalty, tenure intent, and citizenship behaviours. While distributive justice was positively related to affective commitment $(\beta=.24, \mathrm{p}<.001)$, normative commitment $(\beta=0.23, \mathrm{p}>.001)$ and tenure intent $(\beta=.16, \mathrm{p}>.05)$, equity perceptions were unrelated to citizenship behaviours or team loyalty. Thus, we found only partial support for $\mathrm{H} 2$.

H3 proposed that procedural justice perceptions will be positively related to the two forms of commitment, team loyalty, tenure intent, and citizenship behaviours. Similar to equity perceptions, procedural justice was also positively related to affective commitment $(\beta=.39, \mathrm{p}<.001)$, normative commitment $(\beta=.25, \mathrm{p}<.001)$ and tenure intent $(\beta=.14, \mathrm{p}<.05)$ but unrelated to citizenship behaviours or team loyalty. Thus, $\mathrm{H} 3$ also received only partial support.

$\mathrm{H} 4$ suggested that I/C orientations should interact with equity perceptions in influencing employee attitudes. Similarly, H5 proposed that I/C orientations should interact with procedural justice perceptions in influencing employee attitudes. However, in predicting affective commitment, normative commitment, and tenure intent, the statistical significance of the F-ratio test for the incremental variances explained by the interaction terms failed to reach the conventional significance level of 0.05 . Thus, H4 and $\mathrm{H} 5$ did not receive any support in influencing organizational level outcomes of commitment and tenure intent. That is, I/C orientations do not appear to moderate the relationships between justice perceptions and affective commitment, normative commitment, and tenure intent.

However, $\mathrm{H} 4$ and $\mathrm{H} 5$ also proposed that I/C orientations should interact with the two forms of justice perceptions (distributive and procedural justice perceptions) in influencing citizenship behaviours and team loyalty. The incremental variance Fratio tests provided initial support for these hypotheses in that the two cross-product terms explained an additional 3\% of the variances in these outcome variables and were statistically significant. While examining the betas for the two interaction terms, we found that the interaction between I/C orientations and equity perceptions was not significant and hence, $\mathrm{H} 4$ was not supported. However, $\mathrm{H} 5$ received support with respect to pro-social behaviour and team loyalty since the I/C x Procedural justice perceptions interactions were statistically significant. Figure 1 shows the effect of the interaction between $\mathrm{I} / \mathrm{C}$ orientation and perceptions of procedural justice on pro-social behaviour.

The positive and significant beta for the $\mathrm{I} / \mathrm{C}$ orientation $\mathrm{X}$ procedural justice $(\beta=0.86, p<0.01)$ in the equation predicting pro-social behaviour indicated that individualists tended to exhibit greater pro-social behaviour under conditions of higher perceived procedural justice than collectivists. However, under conditions of lower procedural justice perceptions, individualistic orientations tended to produce lesser pro-social behaviours than collectivistic orientations. The pattern of the interaction suggests that when procedural justice increases, individualists are likely to exhibit more pro-social behaviour, whereas collectivists are likely to exhibit less pro-social behaviour. Thus, H5 received support with respect to the pro-social behaviours. 
Figure 1: Moderating effect of individualism orientation on the relationship between procedural justice perceptions and pro-social behaviour

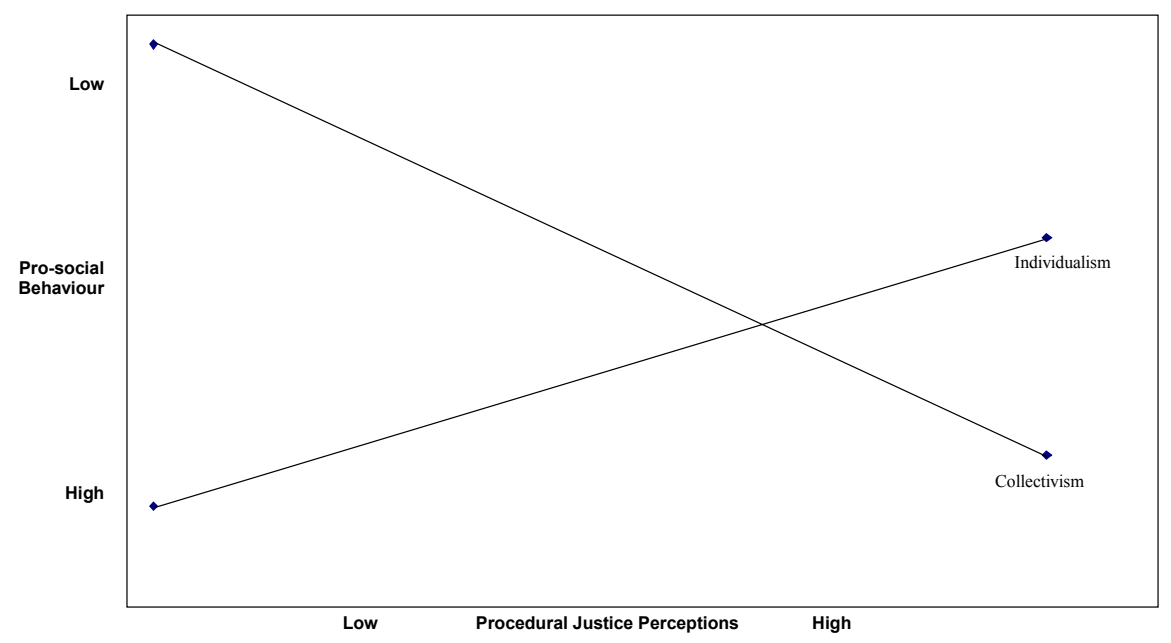

Figure 2: Moderating effect of individualism orientation on the relationship between procedural justice perceptions and team loyality

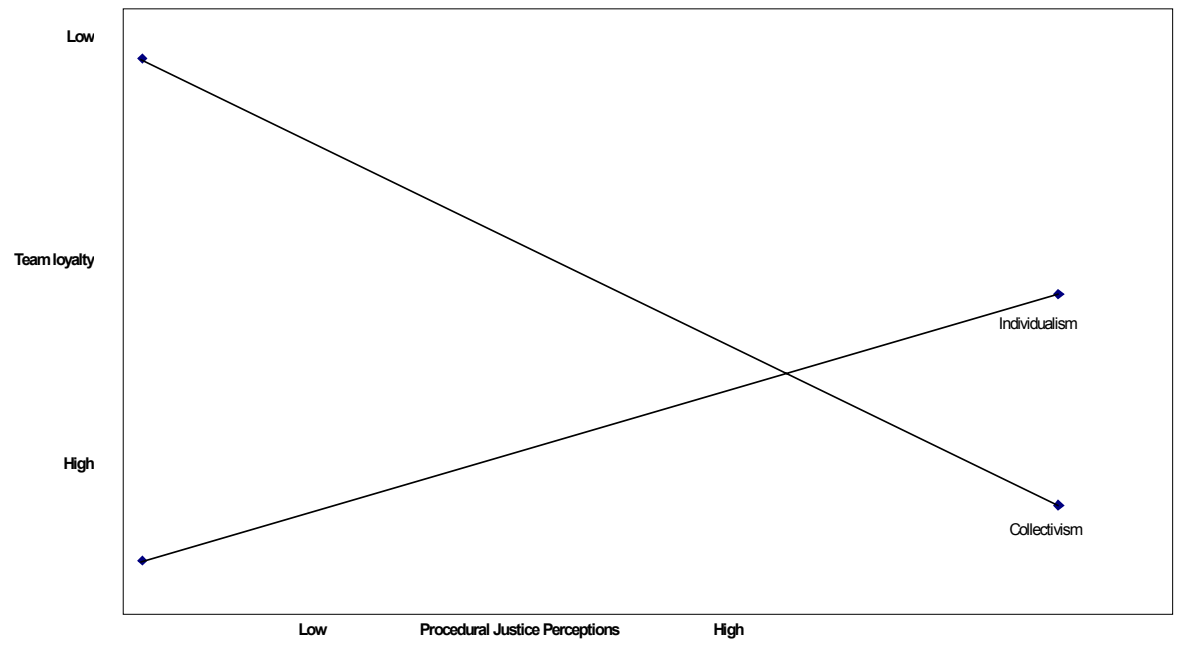

Similarly, in the equation predicting team loyalty, the beta for the $\mathrm{I} / \mathrm{C}$ orientation $\mathrm{x}$ Procedural justice $(\beta=1.029, \mathrm{p}<0.01)$ was positive and significant. Figure 2 shows the effect of the interaction between $\mathrm{I} / \mathrm{C}$ orientation and perceptions of procedural justice on team loyalty.

As suggested by Figure 2, under conditions of lower procedural justice perceptions, individualistic orientations tended to result in lower team loyalty than collectivistic orientations. Similarly, under conditions of higher procedural justice percep- 
tions, individualistic orientations produced greater levels of team loyalty than collectivistic orientations. The pattern of the interaction suggests that when procedural justice perception increases, individualists are likely to exhibit more team loyalty, whereas collectivists are likely to exhibit less team loyalty. Thus, we found support for $\mathrm{H} 5$ with respect to team loyalty also.

To summarize our results, consistent with prior research, we found general support for the hypotheses that I/C orientations affect attitudes towards organizations (affective commitment and tenure intent) and attitudes towards one's team (pro-social behaviour and team loyalty). We also found support that the two forms of justice perceptions - distributive and procedural - positively influence attitudes towards the organization (affective commitment, normative commitment, and tenure intent) but not the team level attitudes of loyalty and pro-social behaviours. Further, we also found that $\mathrm{I} / \mathrm{C}$ orientations do not moderate the relationships between the two forms of justice perceptions and organizational level attitudes such as commitments and tenure intent. However, we found that I/C moderated the relationships between procedural justice perceptions and team-level attitudes of loyalty and pro-social behaviours. Finally, our results also indicate that $\mathrm{I} / \mathrm{C}$ orientations do not moderate the relationships between equity perceptions and team-level attitudes of loyalty and pro-social behaviours.

\section{Discussion}

In the present study, under the assumption that I/C orientations of individuals imply different preferences for procedural and equity perceptions, we examined whether I/C orientations moderated the relationships between justice perceptions and organizational, as well as, team-level attitudes. Our study results suggested some interesting patterns of interactions between the cultural orientations of individuals and justice perceptions in influencing their attitudes towards their organization and teams.

Not surprisingly, individualistic orientations tended to be negatively related to organizational level outcomes of affective commitment and tenure intent. Such results are also consistent with prior studies on I/C orientations (e.g., Gomez-Mejia/Wellbourne 1991; Ramamoorthy/Carroll 1998). Similarly, both distributive and procedural justice perceptions produced positive organizational outcomes in the form of a higher level of commitment and tenure intent by the employees and are generally consistent with prior research on justice perceptions (e.g., Colquitt, et al. 2001). Prior research (Ramamoorthy/Carroll 1998) seemed to indicate that I/C orientations may be related to different aspects of justice perceptions (e.g., equity versus equality; formal procedures versus informal procedures). Thus, one should expect that the effects of same justice principles on organizational outcomes should vary as a function I/C orientations of the individuals. Our present study results seem to suggest that this may not be the case. Regardless of $\mathrm{I} / \mathrm{C}$ orientations of individuals, justice principles seem to have positive effects on organizational outcomes such as affective commitment and tenure intent.

We expected I/C orientations to moderate the relationships between both forms of justice perceptions and team-level attitudes of loyalty and pro-social behaviours. As expected, a higher level of individualism orientation results in lower pro-social behaviour and team loyalty. That is, organizations and teams may not expect individualistically oriented individual to be loyal to the team and/or engage in pro-social behav- 
iours. Some studies (e.g., Ramamoorthy/Flood 2002) suggested that individualistically oriented employees may engage in pro-social behaviours and be loyal to the team when organizations distribute rewards equitably. However, that does not appear to be the case in this study. On the contrary, fair procedures for allocation of rewards such as clear communication of performance standards and opportunity to resolve individual grievances with the supervisor may encourage and reinforce positive team attitudes for individualistically oriented employees. Organizations, however, should be aware that perceptions of procedural justice may have differential effects on individualistic versus collectivistic oriented employees' attitudes. While organisations that strive to instil a culture of procedural fairness may motivate individualists to exhibit higher levels of pro-social behaviour and team loyalty, it may result in an opposite effect for collectivists.

We can also propose that commitment and tenure intent were reactions to organizations rather than to immediate work behaviours such as pro-social behaviours and team loyalty. It is possible, therefore, that procedural justice principles may have different effects on organizational and team-level outcomes. While procedural justice principles based on individual rights seem to result in favourable organizational-level outcomes, they may tend to produce unfavourable outcomes on the immediate work behaviours in teams depending on the team composition. Future studies should examine the interactions between cultural orientations and justice principles with a different sample in a different setting and measuring both organizational level outcomes and other team-level variables such as team identity, team commitment, and individual effort in teams. Till then, our results should be considered tentative and suggestive rather than definitive.

These results should be of particular interest to multinational organisations. Most of these emerge from individualistic cultures and when they expand into other countries with a greater emphasis on collectivist orientations, they often, initially at least, transfer policies and practices directly from the country of origin to the host nation. Thus transferring policies and procedures across borders from a predominantly individualist culture to a more collectivist culture or vice versa may produce unanticipated and undesirable effects.

\section{Limitations and conlusions}

The present study, to our knowledge, is one of the first studies to examine the interactions between I/C orientations and justice principles in impacting employee attitudes. However, we would like to suggest a few limitations of this study. As data were gathered from participants using a single survey questionnaire response bias cannot be totally ruled out. However, preliminary results obtained in our study using a survey methodology may be suggestive of a fruitful research agenda that can be pursued by organizational scholars and cross-cultural researchers. A second issue related to our study concerns the generalisability of our results to other groups of employees and cultures. Since we used blue-collar, manufacturing employees in this sample, whether the results are generalisable to other types of employees, such as professional or managerial staff should be an agenda for future research. Finally, the sample for our study came from a single national culture, namely Ireland. Based on theory, we are 
reasonably confident that the results may be similar in different cultures. However, it would be interesting to replicate or extend this research to a more heterogeneous, cross-national sample to further validate our findings.

\section{References}

Adams, J. S. (1965): Inequitiy in social exchange. In: L. Berkowitz (Ed. ), Advances in Experimental Social Psychology. New York: Academic Press: Vol. 2: 267-290.

Ahmad, K. (2004): Choice of allocation norms and perceived fairness of Malaysian corporate management. In: International Journal of Commerce and Management, 24(2): 15-31.

Aquino, K./Griffith, R./Allen, D./Hom, P. (1997): Integrating justice constructs into the turnover process: A test of a referent cognitions model. In: Academy of Management Journal, 40: 1208-1227.

Berman, J. J./Murphy-Berman, V./Singh, P. (1985): Cross-cultural similarities and differences in perceptions of fairness. In: Journal of Cross-Cultural Psychology, 16: 55-67.

Bond, M. H./Leung, K./Choi, K. (1982): How does cultural collectivism operate? The impact of task and maintenance contributions on reward distribution. In: Journal of Cross-Cultural Psychology, 13(2): 186-200.

Clugston, M./Howell, J. P./Dorfman, P. W. (2000): Examining organizational commitment across cultural dimensions. In: Journal of Management, 26: 5-30.

Cohen-Charash, Y./Spector, P. E. (2001): The role of justice in organizations: A meta-analysis. In: Organizational Behavior and Human Decision Processes, 86: 278-321.

Colquitt, J./Conlon, D./Wesson, M./Porter, C./Ng, K. (2001): Justice at the millennium: A meta-analytic review of 25 years of organisational justice research. In: Journal of Applied Psychology, 86: 425-445.

Cropanzano, R./Greenberg, J. (1997): Progress in organizational justice: tunnelling through the maze. In: International Review of Industrial and Organizational Psychology, 12: 317-72.

Deutsch, M. (1975): Equity, equality, and need: What determines which value will be used as the basis of distributive justice? In: Journal of Social Issues, 31(3): 137-149.

Fields, D./Pang, M./Chiu, C. (2000): Distributive and procedural justice as predictors of employee outcomes in Hong Kong. In: Journal of Organizational Behavior, 21: 547-562.

Flaherty, K. E./Pappas, J. M. (2000): The role of trust in salesperson-sales manager relationships. In: Journal of Personal Selling and Sales Management, 20: 271-278.

Gomez-Mejia, L. R./Welbourne, T. (1991): Compensation strategies in a global context. In: Human Resource Planning, 14: 29-41.

Greenberg, J. (1990): Employee theft as a reaction to underpayment inequity: The hidden cost of pay cuts. In: Journal of Applied Psychology, 75: 561-568.

Greenberg, J. (2001): Studying organizational justice cross-culturally: Fundamental challenges. In: The International Journal of Conflict Management, 12(4): 365-375.

Hendrix, W./Robbins, T./Miller, J./Summers, T. P. (1999): Procedural and distributive justice effects on turnover. Paper presented at the Annual Meeting of the Society for Industrial and Organizational Psychology, Atlanta, GA.

Hofstede, G. (1980): Culture's Consequences: International Differences in Work-Related Values, Beverly Hills, CA: Sage.

Kim, W. C./Mauborgne, R. (1997): Fair process: Managing in the knowledge economy. In: Harvard Business Review 75: 65-75.

Kim, W. C./Mauborgne, R. (1998): Procedural justice, strategic decision-making, and the knowledge economy. In: Strategic Management Journal 19: 323-338.

Kim, I. K./Park, H./Suzuki, N. (1990): Reward allocations in the United States, Japan, and Korea: A comparison of individualistic and collectivistic cultures. In: Academy of Management Journal, 33: 188-98.

Konovsky, M. A./Cropanzano, R. (1991): Perceived fairness of employee drug testing as a predictor of employee attitudes and job performance. In: Journal of Applied Psychology, 76: 698-707.

Lee, C./ Pillutla, M./Law, K. S. (2000): Power distance, gender and organizational justice. In: Journal of Management, 26(4): 685-704.

Leventhal, G. S. (1976): The distribution of rewards and resources in groups and organizations. In: L. Berkowitz/W. Walster (Eds. ): Advances in experimental social psychology. New York: Academic Press: $91-131$. 
Masterson, S. S./Lewis, K./Goldman, B. M./Taylor, M. S. (2000): Integrating justice and social exchange: The differing effects of fair procedures and treatment on work relationships. In: Academy of Management Journal, 43(4): 738-748.

Meyer, J. P./Allen, N. J. (1991): A three-component conceptualization of organizational commitment. In: Human Resource Management Review 1(1): 61-89.

Moorman, R. H. (1991): Relationship between organizational justice and organizational citizenship behaviors: Do fairness perceptions influence employee citizenship? In: Journal of Applied Psychology, 76: 845-855.

Mowday, R. T./Porter, L. W./Steers, R. M. (1979): The measurement of organizational commitment. In: Journal of Vocational Behavior, 14: 224-247.

Parkes, L. P./Bochner, S./Schneider, S. K. (2001): Person-organization fit across cultures: An empirical investigation of individualism and collectivism. In: Applied Psychology: An International Review, 50: 80-108.

Pedhazur, E. J. (1982): Multiple regression in behavioral research: Explanation and prediction (2nd ed. ). Fort Worth, TX: Harcourt Brace.

Phillips, J. M (2002): Antecedents and consequences of procedural justice perceptions in hierarchical decision-making teams. In: Small Group Research, 31(1): 32-64.

Pillai, R../Williams, S. E./Tan, J. J. (2001) are the scales tipped in favor of procedural or distributive justice? An investigation of the U. S. , India, Germany, and Hong Kong (China). International Journal of Conflict Management, 12(4): 312-332.

Ramamoorthy, N./Carroll, S. J. (1998): Individualism/collectivism orientations and reactions toward alternative human resource management practices. In: Human Relations, 51: 571-588.

Ramamoorthy, N. ,/Flood, P. (2002): Employee attitudes and behavioral intentions: A test of the main and moderating effects of individualism - collectivism orientations. In: Human Relations, 55(9): 1071-1096.

Ramamoorthy, N./Flood, P. (2004): Gender and employee attitudes: The role of organizational justice perceptions. In: British Journal of Management, 15(3): 247-258.

Ramamoorthy, N./Flood, P./Slattery, T./Sardessai, R. (2005): Determinants of innovative work behaviour: Development and test of an integrated model. In: Creativity and Innovation Management, 14(2): 142-150.

Rhoades, L./Eisenberger, R./Armeli, S. (2001): Affective commitment to the organization: The contribution of perceived organizational support. In: Journal of Applied Psychology, 86: 825-836.

Roberts, J. A./Coulson, K. R./Chonko, L. B. (1999): Salesperson perceptions of equity and justice and their impact on organizational commitment and intent to turnover. In: Journal of Marketing Theory and Practice 7: 1-16.

Spector, P. E./Fox, S. (2002): An emotion-centered model of voluntary work behavior: Some parallels between counterproductive work behavior (CWB) and organizational citizenship behavior (OCB). In: Human Resources Management Review, 12: 269-292.

Sweeney, P. D./McFarlin, D. B. (1993): Workers" evaluation of the "ends" and the "means": An examination of the models of distributive justice and procedural justice. In: Organizational Behavior and Human Decision Processes, 55: 23-40.

Thibaut, J./Walker, L. (1975). Procedural justice: A Psychological View. New York: Wiley.

Tremblay, M./Sire, B./Balkin, D. B. (2000): The role of organizational justice in pay and employee benefit satisfaction, and its effects on work attitudes. In: Group and Organization Management, 25: 3, 269-290.

Vandello, J. A./Cohen, D. (1999): Patterns of individualism and collectivism across the United States. In: Journal of Personality and Social Psychology, 77: 279-292.

Wagner, J. A. (1995): Studies of individualism-collectivism: Effects on cooperation in groups. In: Academy of Management Journal, 38, 152-172.

Williams, S./Pitre, R./Zainuba, M. (2002): Justice and organizational citizenship behaviour intentions: fair rewards (v) fair treatment. In: Journal of Social Psychology, 142(1): 33-45.

Zellars, K./Briu, Y./Bratton, V./Brymer, R./Perrewe, P. (2004): An examination of the dysfunctional consequences of organizational injustice and escapist coping. In: Journal of Managerial Issues, 16(4): 528-544. 